\title{
South Africa's informal backyard rental sector: linkages with Smart Growth and sustainability concepts
}

\author{
L. G. Lategan \& E. J. Cilliers \\ Unit for Environmental Sciences and Management, \\ Urban and Regional Planning, North-West University, South Africa
}

\begin{abstract}
Low-cost housing development in South African's post-Apartheid era is overwhelming; dealing with a fragmented and segregated urban inheritance and a housing demand which exceeds delivery capacity. In response to insufficient delivery, the destitute have turned to informal backyard renting. Backyard dwellings can accommodate a multitude of tenants in one or two roomed wood, or corrugated iron structures, constructed by tenants in the backyards of homes provided by government housing schemes. The backyard rental sector is widely described as unsustainable; however, this paper argues that the sector may, in principle, be one of the most sustainable aspects of South Africa's housing development culture. This paper analyses the benefits and disadvantages related to the continued growth of the informal backyard sector and explores the value of the sector as a supporter of Smart Growth through infill development, increased densities and as a countermeasure to urban sprawl. In an attempt to evaluate the sustainability of backyard living, the living conditions and additional pressures placed on infrastructure and transport networks, as a result of backyard rentals, are examined. The main research question to answer is: Is Smart Growth supported by the informal backyard rental sector and what sustainability pressures are exerted as a result thereof? The research for this paper includes surveys conducted in the case study area of Oudtshoorn in South Africa's Western Cape Province, interviews with relevant stakeholders and an evaluation of existing literature. The conclusions drawn may provide evidence for the need to regulate and develop the backyard rental sector in order to improve the lives of backyarders and the efficiency of the South African city.

Keywords: Smart Growth, backyard rentals, low-income housing, sustainability.
\end{abstract}




\section{Introduction}

South Africa's troubled past, rooted in the oppressive segregation brought about by the policy of Apartheid, continues to obscure the country's current and future urban development prospects [1]. South African planners face the segregated, dispersed and fragmented urban structures they inherited, as well as a growing demand for low-cost housing and limited resources to meet these needs [1, 2].

In an attempt to compensate for past injustices the South African government focuses on delivering housing units in large numbers. Subsequently the pressure to deliver in large quantities has superseded quality and sustainability considerations $[3,4]$, such as social inclusion and well-being, economic growth and environmental protection. The costs related to large scale housing development, force new low-cost projects to the urban periphery, where land is more freely available and attained at more competitive prices. Since the advent of democracy in 1994, low-cost housing delivery has mostly involved building serviced townships on urban peripheries, thus perpetuating the phenomenon of urban sprawl and the ails associated therewith [5, 6]. According to Pieterse [7] (cited in Fieuw [6]) the failure of the democratic government to transform the urban structures of the past has intensified urban sprawl. Urban sprawl, in this sense, is defined as the outward spread of the city and its suburbs to the periphery, generally on rural land, due to low-density development, which infers an extreme dependence on automobiles and the segregation of urban land uses [8].

The unsustainable growth patterns associated with the South African city cannot be exclusively attributed to the planned low-cost housing extensions delivered by authorities. The disjuncture between the need for affordable housing and limited governmental capacity to meet this need, has manifested itself in the establishment of immense informal 'shanty town' settlements. In 2011 a total of $1,864,386(13.84 \%)$ out of $13,467,352$ households could be classified as informal [9]. Informal settlements are frequently located on the urban fringe or on undeveloped parcels of land located within the urban periphery. These parcels are often invaded illegally as a result of more favourable locations, but are not provided with basic services. Thus informal settlements do not offer much in the way of access to basic services, but may be better located in terms of existing socio-economic opportunities such as employment and leisure nodes.

However, the formal delivery of low-cost housing units also infers various problems. Housing beneficiaries, although grateful, are often dissatisfied with the location, quality and maintenance costs associated with their subsidised units. As a result countless beneficiaries leave their new homes in order to live in informal settlements [10]. Although these settlements suggest substandard living conditions, residents live there for free and may take advantage of reduced transportation costs to access employment opportunities and socio-cultural amenities.

A further problem is related to housing beneficiaries who (in some cases) capitalise on their new property assets by generating a rental income [5, 11, 12]. This phenomenon is known as the informal backyard rental sector. 


\section{The informal backyard rental sector}

Where low-cost housing projects are more favourably located, a uniquely South African phenomenon has manifested itself. The informal backyard rental sector established itself as an unmistakable component of the country's urban landscape and as an equally significant contributor to South Africa's housing stock. The backyard rental phenomenon was established in the 1980s as a response to the lack of adequate accommodation close to economic opportunity nodes [13]. The peripheral locations of most subsidised housing schemes delivered in the PostApartheid era, only intensified the established trend of informal renting. The backyard sector is defined by informal structures which occupy surplus space, shared with a formally developed housing unit within a formal and fully serviced housing area [14]. Although informal rentals may be found across the globe, the segment of the market which allows for the erection of structures, built entirely by tenants, on spaces rented in the backyards of landlords, is a uniquely South African manifestation [15]. Backyard dwellings are most frequently constructed from salvaged materials such as wood and corrugated iron sheeting with scraps of cardboard as insulation [16]. Backyard structures are generally comprised of only two rooms, shared by both sexes and all ages of one or more families, for all daily living activities [14]. One may be able to compare the physical structures occupied by backyard renters to the dwellings found in the disenfranchised informal townships located across South Africa. However one major benefit distinguishes the two: backyard renters still enjoy some access to the services provided to their landlords. In general, backyard settlers enjoy better access to services than those in informal settlements [17].

Thus at its core, the spatial arrangements introduced by the informal backyard rental sector rest on infill development practices. Infill development is defined as the development of underutilised parcels of land located within an already developed urban area. This definition infers that the parcels developed or filled in were at least partially developed before new or added uses were introduced [18], as inferred by the development of informal rental accommodation adjacent to already serviced and developed formal housing units. The benefits related to infill development and the increased densities introduced thereby, are advocated by the Smart Growth movement [18].

The Smart Growth movement is characterised by initiatives focussed on higher densities, increasing the supply of affordable housing, the preservation of green space and agricultural uses, reduced road construction which is compensated for by transportation alternatives and balanced development between urban centres and peripheries [8, 19].

Thus Smart Growth presents an alternative to dispersed, automobile dependent development outside existing urban areas. Various studies agree that sprawl is more costly than Smart Growth [20].

Smart Growth policies are inclined to reduce various costs related to modern land use development patterns. These savings are brought about by reduced land coverage, private vehicle ownership and travel distances, as well as an increase in the use of alternative and public modes of transport [21]. 
The informal backyard rental sector and the Smart Growth movement both impact at a collective and individual level, by providing benefits and disadvantages to individual residents and the broader community. The backyard sector's influence is felt by entire neighbourhoods, communities and cities and also by backyard tenants, their landlords and the authorities charged with managing and improving urban living conditions. Thus it is necessary to study the sector's spatial influence as well as its impacts on social, economic and environmental sustainability where these issues are clearly visible. In this regard the case study area of Oudtshoorn was selected based on the new, sprawling housing development taking place there as a result of an unstable informal backyard rental sector.

\section{Oudtshoorn, Western Cape, South Africa}

The following section will attempt to demonstrate the value of the informal backyard rental sector as a Smart Growth instrument of infill development, increased density and ultimately a countermeasure to urban sprawl. In addition the backyard rental sector's influence on social, economic and environmental sustainability will be discussed, as observed in the case study of Oudtshoorn in South Africa's Western Cape Province. Oudtshoorn is known as the capital of the Klein Karoo, a scenic part of the Western Cape Province, known for its diverse landscape and agriculture- and tourism based economy.

Oudtshoorn is called home by 92,963 residents, according to the 2011 census, and covers a total area of $29.24 \mathrm{~km}^{2}$, or 2924 Hectare [9]. Until as recently as 2010, Oudtshoorn's residents were housed in formally developed private or subsidised units, backyard dwellings and a small number of informal structures, sporadically located throughout the extensions of Bongulethu and Bridgeton. In 2011 the South African census recorded the number of informal households as 1938 (8, 13\%), formal household as $3711(15,58 \%)$ and very formal households as 18099 (75, 97\%), for Oudtshoorn [9]. The town never faced a substantial agglomeration of informal structures which could be defined as an informal settlement or shanty town. However the town's housing profile was transformed forever by the end of 2011, after large scale land invasion took place on its south eastern border. Now for the first time in its history, Oudtshoorn faced managing, controlling and servicing an informal settlement. This settlement was originally dubbed 'Riemvasmaak' by locals, but is now known as Rose Valley.

Rose Valley may not be significant in size when compared to the informal townships found in larger towns and metros, but it does provide the ideal opportunity to study the effects of an unstable backyard rental sector.

The majority of Rose Valley's residents did not move to the area from outside Oudtshoorn's borders, but were instead motivated by the unstable conditions related to the backyard dwellings they previously occupied.

A survey conducted in July of 2012 found that $68 \%$ of participants relocated to Rose Valley from the backyards of formal dwellings elsewhere in Oudtshoorn [22]. These settlers were either evicted by their landlords or chose to relocate to an area which would potentially provide the opportunity to be housed under 
government subsidised programmes [23]. It is important to note that many of the Rose Valley settlers were lured to the area by politicians who promised housing in return for votes [24]. However the unstable condition of the informal backyard rental sector did little to deter the process. The relocation of these settlers, from backyards where they contributed to increased densities and benefitted from exiting services, to the barren landscape of Rose Valley on Oudtshoorn's outskirts, contributed to urban sprawl and its associated ails. The following section describes this migration's influence on sustainability and subsequently the value of the backyard rental sector as a supporter of the Smart Growth movement.

\section{Backyards, Smart Growth and sustainability: an Oudtshoorn perspective}

\subsection{Social interaction and strife}

The site occupied unlawfully by the Rose Valley settlers was incorporated into Oudtshoorn's urban edge in the Apartheid decade of the 1980s [23, 24]. However, extending housing provisions in this area and endorsing the sprawl inferred thereby, placed residents too far from the established areas of opportunity such as the town centre and its amenities [25].

In addition, housing development here further enforced the Apartheid city structure, which segregates communities according to race and economic standing [23]. Various authors are unanimous in their verdict, stating that urban sprawl, and therefore low-density development, contributes to the segregation of different economic classes and reduces social interaction [8, 26, 27]. In can thus be assumed that the current housing phenomenon in Rose Valley also impacts greatly on social sustainability. It is crucial to provide settlements which are accessible, inclusive and compact, in order to deliver socially sustainable communities [24]. Thus, providing development on the urban outskirts is not socially sustainable as this trend promotes a dependence on expensive public transport or infers excessive distances to be travelled by pedestrians, is exclusive in its racial segregation and incorporation into the urban fabric, or sprawled to the extent of utter ineffectiveness. This is also true for the Rose Valley case study, where the sprawl and segregation brought about by the settlement, as a result of migrations from backyard dwellings, affects social sustainability.

Preventing sprawl, through the infill practices established by the informal backyard rental sector, may promote social sustainability under the banner of the Smart Growth movement. Smart Growth initiatives may provide several benefits related to social sustainability. Smart Growth's reduced sprawl and increased densities may improve transport options for those without access to private vehicles [21].

This applies specifically in the lowest-income areas of South Africa, where private vehicle ownership is scarce and people are forced to make use of an ineffective and sometimes expensive public transport system or on walking long distances to their destinations. 
Apartheid's tentacles have extended their reach to current urban development, and still have a tight grip on especially the social dimension of urban living. In this regard promoting social cohesion in support of social sustainability is paramount. Social cohesion is most promoted by the reduced levels of automobile travel associated with Smart Growth development and the interactions made possible by increasing walking and cycling opportunities. Residents of more walkable neighbourhoods are more likely to know their neighbours, be socially engaged and politically and physically active [21]. The South African township is neither known for its docile street life nor the lack of interaction between neighbours. However providing more walkable and compact neighbourhoods extends interaction beyond immediate neighbours and street blocks and weaves a web of community interconnectivity. This also supports the South African concept of Ubuntu. Ubuntu is a 'particular African worldview in which people can only find fulfilment through interacting with other people' [29].

Thus the more compact spatial arrangements, promoted by the informal backyard rental sector, theoretically promote social sustainability. Unfortunately the conditions under which backyard tenants etch out their daily existence, is less favourable. In Oudtshoorn, as in the rest of South Africa, backyard living infers several social concerns, specifically related to crime and violence. A definite increase in crime levels can be observed in areas where backyard dwellings are more prevalent [30]. This can be attributed to a number of factors which include idleness, poverty, unemployment and substance abuse. Health is an important aspect to be considered when examining social sustainability [28]. The health issues related to backyard habitation are widely recognised [31]. Crouse [32] states that the lack of cross-ventilation and the cold and wet conditions often found in a backyard dwelling worsens respiratory ailments such as tuberculosis, which is also contagious. Should other infectious diseases such as meningitis break out, the proximity in which many backyarders live may have epidemic consequences [33].

In addition conflict and backyard renting seem to go hand in hand [22]. Landlords and tenants are commonly in disagreement, which infers unstable living arrangements to the detriment of social sustainability. The number of Rose Valley sellers who moved to the area as a result of tainted landlord-tenant relationships, attests to this fact. As a result of the tension often associated with the backyard landlord-tenant relationship, $60 \%$ of Rose Valley survey participants stated that they would not consider opening their yards to backyard settlers once they received their formal housing units [22].

Sustainable development, although greatly dependant on social sustainability cannot be considered without acknowledging the importance of the economic and financial issues, which either support or threaten present and future quality of life.

\subsection{Economic strains and gains}

Housing development will always require substantial financial investments. However these costs can be managed and reined in when projects are 
appropriately planned. In this regard planning can be divided into two sections of equal importance and value. Firstly financial planning; as it is vital that new housing projects are aligned with budget cycles and future development plans. Secondly, physical planning which refers to cost-effective location choices, layout options and densities. The sudden unlawful occupation of the Rose Valley settlement and the response to house settlers complied with neither.

From an economic perspective the additional pressure exerted by the unlawful invasion of the Rose Valley area is immensely straining. The development budget per Rose Valley stand is estimated at approximately R85,000 $( \pm \$ 8,500$ USD) [24].

With 850 stands, this infers a total budget of R72, 25 million, or $\$ 7,225$ million (USD). The sudden need to house Rose Valley's settlers imposed great strain on already pressured housing budgets. In 2012 the housing list for the broader Oudtshoorn area contained 14000 prospective beneficiaries, each one just as desperate and in need as the next [25]. In 2012 the Oudtshoorn Local Municipality's Division of Revenue Allocation (DORA), which is geared towards housing development, was only R13 million ( $\$ 1.3$ million USD) per annum, which translated to the delivery of only 250 new units per year. Even if the authority managed to quadruple its delivery capacity, it would still take fourteen years to house the 2012 backlog. Thus the sudden and concentrated demand for housing personified by the Rose Valley occupation and the demands and expectations of its residents, seems to place immeasurable strain on an already fragile and quite depleted system.

However the location of the Rose Valley settlement as an extension of Oudtshoorn's built area does not singlehandedly promote increased development expenditure. Instead the unsuitable conditions on site, which do not encourage cost-effective low-income housing development, seem to impose greater costs. For example infrastructure expenditure on road construction is forecast to increase due to the slope of the area [24]. The undulating landscape further necessitates the construction of an additional pumping station of approximately R3 million ( $\pm \$ 300,000$ USD). These costs are further exacerbated by the lowdensity development which typifies traditional RDP-based housing projects such as Rose Valley. The provision of basic services is more expensive, the less dense the area [26, 34, 35].

The somewhat distant location of the new settlement in relation to existing nodes and opportunities will infer additional development and operating costs to be borne by both the local authority and residents. In an attempt to provide Rose Valley's beneficiaries with some access to employment opportunities and commercial amenities, an additional entrance connection on the N12 motorway has been approved. Furthermore a public transport route operated by South Africa's traditional people mover, the minibus taxi, will be provided [24].

Thus residents will be forced to make use of expensive public transport and may be inconvenienced by the distance they will have to travel, as observed in numerous other sprawled housing developments [36]. Many who find work as domestic workers and gardeners will have to walk the more than $8 \mathrm{~km}$ to the 
nearest higher-income suburb where they are employed, because their wages will not cover travel costs.

In an attempt to counteract the travel impacts related to the Rose Valley Extension, the approved layout concept makes provision for commercial nodes to be established within the new extension, thus providing some employment and reducing the need to travel to Oudtshoorn's central business district (CBD) [24].

However when the need arises to travel to these existing nodes and amenities, the effects of sprawl on travel distance and costs will be felt, as it is proven that sprawl increases per capita vehicle travel and expenditure as well as congestion related delays [21].

As previously established the infill nature of the informal backyard rental sector as a countermeasure to urban sprawl may provide many of the benefits captured by the Smart Growth development approach. The cost of providing infrastructure and services is considerably higher for populations in new sprawling developments when compared to costs imposed by Smart Growth principles or where infill development takes place [37]. Smart Growth development provides reduced transportation related costs to both authorities and the public by reducing travel times, providing improved travel options such as cycling, shorter walking distances and less expensive public transport opportunities [21]. The costs related to urban sprawl provide leverage for Smart Growth programmes which advocate compact, high-density development in both academic and applied planning spheres [38]. Various studies agree that sprawl is more costly than Smart Growth, consistently proving that lower-density development increases both public and private development and operating costs [20].

The informal backyard rental sector makes use of the infrastructure investments already in place in established communities. However it must be noted that not all backyarders enjoy full access to all the services provided to their landlords. In Oudtshoorn infrastructure provisions do not extend to backyard settlers and in this regard backyarders are dependent on the access granted by main dwelling landlords for their basic service needs. The majority of conflicts between tenants and landlords can be attributed to disagreements regarding rents payable, access to services, including sanitation, and the volume of electricity and water (from the main house) to which backyard renters are entitled [39]. In addition the drastic increase in densities and therefore users to be serviced may place immense pressure on existing infrastructure networks which may infer maintenance and upgrading costs.

The informal backyard rental sector also offers the opportunity for financial gain. The sector provides a rental income to millions of home owners, many of whom are unemployed or work for minimum wage. In Oudtshoorn backyard renters generally pay anything from R50 to R400 ( \pm \$5 to \$40 (USD)) to landlords for the spaces they occupy [39].

Thus the sector provides home owners with an additional income which can be used for maintenance or improvements, or to at least partially cover living expenses. It also presents an affordable housing option to many who would otherwise be destined to call informal shanty towns home. Informal rentals 
located in backyards do not only impact on social and economic conditions, but also infer certain environmental influences.

\subsection{Environmental conservation and deterioration}

According to Brummer [8], urban sprawl has continued to manifest due to an overemphasis on the importance of economic advancement with a disregard for environmental protection. As a practical example, the illegal invasion of the Rose Valley area imposed certain environmental transgressions. The majority (77\%) of the Oudtshoorn Local Municipal area is covered by shrubland and low Fynbos [9], which is highly valued from an ecological perspective. The land situated beyond Rose Valley's borders is currently used for agricultural purposes, but is not extremely productive. However these fields also contain some fairly important pockets of indigenous vegetation which is protected under environmental law. In fact the Oudtshoorn Local Municipality faced charges from the Department of Environmental Affairs and Development Planning in lure of the illegal clearing of ecologically sensitive areas to make way for the Rose Valley settlement. In this regard the Rose Valley settlement will not expand any further after formal dwellings have been developed within the settlements current borders [24].

Cities cannot expand housing provisions without sacrificing open space and agricultural land in already populated areas, or on the periphery [18, 19]. The Smart Growth movement attempts to strike a balance between unavoidable urban growth and protecting the valuable natural and cultivated green environment [20]. In this regard the movement focuses on the preservation of agricultural land and green spaces by promoting higher densities [8]. The reduction in total development area required due to an increase in densities, provides for the establishment, growth and preservation of more productive and valuable uses such as agricultural uses and natural habitats [21]. In addition the increased densities and reduced levels of urban sprawl promoted by Smart Growth may reduce carbon emissions and promote energy savings which are directly transferred to consumers and the environment [19, 21]). However more compact development may also infer certain environmental threats, as can be observed in Oudtshoorn's backyard rental sector. Another issue to consider is the construction of the backyard structures, which mainly consist of wood fragments which are discarded by local timber yards and insulated with cardboard, as in the case of the Oudtshoorn case study. The use of recycled materials such as discarded wood may bode well from an environmental perspective, but also infers certain risks. For example wood structures are often not watertight and more importantly are fire hazards.

House fires are a common sight in Oudtshoorn's backyards, mostly as a result of a lack of electricity and the unsupervised use of candles; and secondly as a result of informal electricity connections which are exposed to extreme weather conditions [39].

In some cases electrical wire barely suitable for indoor use is used to connect backyard structures with main dwelling units, mainly to overloaded sockets 
indoors [32]. The resulting fires spread rapidly from yard to yard, leaving children especially vulnerable.

As a result many backyarders sever their connections and choose to live without electricity rather than risk their own or the lives of their children. These fires increase air pollution levels. It can thus be assumed that the spatial location of backyard rentals and the reduced levels of sprawl promoted by the sector reduce risks to environmental resources and sustainability, but may still induce certain activities which threaten the natural environment.

\section{Conclusion}

The spatial arrangements promoted by South Africa's informal backyard rental sector, as an instrument of infill development, provide many of the spatial advantages and possible cost savings related to the Smart Growth movement. In this regard urban sprawl is countered, more effective use is made of existing infrastructure provisions, social segregation and fragmentation is averted and environmental resources are spared. The backyard rental sector provides these benefits by offering shelter to hundreds of thousands, if not millions of South Africans, who would otherwise settle in informal shanty town townships whilst they wait for local government subsidised housing. These informal townships are generally established through illegal land invasions either on or beyond the urban periphery, or on sites which are not ideally suited to development, as demonstrated by Oudtshoorn's Rose Valley case study. In Rose Valley the majority of settlers migrated from backyards, thus emphasising the need to stabilise and regulate the informal backyard rental sector. Although informal backyard rentals encourage higher densities and more compact development which combats urban sprawl, the sector is not sustainable in its current form. South Africa's backyards need to be regulated, protected, serviced and managed if social, economic, environmental and spatial sustainability is to be established. Thus the informal backyard rental sector presents the opportunity to capitalise on an established rental and high-density development culture, but not without further investment to solidify sustainable development practices.

\section{References}

[1] Holomisa, B.H., www.unep.org/ourplanet/imgversn/81/holomisa.html

[2] Makamu R.I.., Background of housing delivery process in South Africa, University of Limpopo, pp. 1-113, 2010.

[3] Mahomed, L., A review of urban low cost housing projects in South Africa through a sustainability lens. Proceedings: Strategies for a sustainable Built Environment, Pretoria, pp. 1-8, 2000.

[4] Isaacs, I. and Naido, E., www.iol.co.za/news/south-africa/how-tobuildquality-houses-for-r55-000-1.466848.

[5] Goebel, A., Sustainable urban development? Low-cost housing challenges in South Africa, Habitat International, 31(3-4), pp. 291-302, 2007. 
[6] Fieuw, W.V.P. Informal Settlement Upgrading in Cape Town's Hangberg. Local Government, Urban Governance and the 'Right to the City', Master of Philosophy, Faculty of Economics and Management Sciences, Stellenbosch University. http://scholar.sun.ac.za

[7] Pieterse, E., Post-Apartheid Geographies in South Africa:Why are urban divides so persistent? Interdisciplinary, Debates on Development and Cultures: Cities In Development-Spaces, Conflicts And Agency, Leuven University, pp. 1-15, 2009.

[8] Brummer, A., The Effects of Urban Sprawl on Daily Life, Master of Transportation Program South Carolina State University, pp. 1-9, 2012.

[9] Global Insight South Africa, Regional Explorer. www.globalinsight.co.za.

[10] Tuxford, K., Cape Chameleon: Housing in South Africa, why are people still living in shacks? 13(1), 2011.

[11] UN-Habitat. Land in support of sustainable urbanisation third African Ministerial Conference on housing and urban development: Bamako Mali, pp. 1-28, 2011.

[12] Victor, T., The Challenges of Eradicating Informal Settlements in South Africa by 2014. The Case of Seraleng Sustainable Human Settlement, Rustenburg Local Municipality, North West, Master of Science thesis: University of the Witwatersrand, Johannesburg, pp. 1-140, 2009.

[13] Ebrahim, Z., www.sahf.org.za/Images/2011\%20Proceedings/PowerPoints/ Zohra_Ebrahim.pdf

[14] Lemanski, C., Augmented informality: South Africa's backyard dwellings as a by-product of formal housing policies, Habitat International, 33(4), pp. 472-484, 2009.

[15] Crankshaw, O., Gilbert, A. and Morris, A., Backyard Soweto, International. Journal of Urban and Regional Research, 24(4), pp. 841-857, 2000.

[16] Morange, M., Backyard shacks: the relative success of this housing option, Urban Forum, 13(2), pp. 3-25, 2002.

[17] The Social Housing Foundation. Shack Rentals in South Africa, pp. 1-16, 2010.

[18] McConnell, V. and Wiley, K., Infill Development: Perspectives and Evidence from Economics and Planning, Resources for the Future RRF, pp. 1-37, 2010.

[19] SCANPH, Southern California Association of Non-Profit Housing SCANPH: Density Guide For Affordable Housing Developers, 2003.

[20] Osman, S., Nawawi, A.H. and Abdullah, J., Urban Sprawl and Its Financial Cost - A Conceptual Framework, Asian Social. 4(10), pp. 1-12, 2008.

[21] Litman T.A., Smart Growth savings what we know about public infrastructure and service cost savings, and how they are misrepresented by critics, Victoria Transport Policy Institute, pp. 1-31, 2005.

[22] Lategan, L.G., Ciliers, E.J. and Cornelius, G.S., A study of the South African low cost housing environment with reference to possible alternative approaches. South African Planning Institute, Planning Africa Conference: Durban, pp. 1-12, 2012. 
[23] Bruce, S. Personal communication. 10 July 2012, Acting Town Planner: Oudtshoorn, SA.

[24] Eastes, J. Personal communication, 12 August 2013, Chief Town Planner: Oudtshoorn, SA.

[25] Juthe, G. Personal communication, 6 September 2012, Director of Community Services: Oudtshoorn, SA.

[26] Solé-Ollé, A. and Rico, M.H., Does Urban Sprawl Increase the Costs of Providing Local Public Services? Evidence from Spanish Municipalities. Urban Studies, 47(7), pp. 1513-1540, 2010.

[27] Bajari, P. and Kahn, M.E., Private and Social Costs of Urban Sprawl: The Lot Size Versus Commuting Trade-off, working paper, pp. 1-42, 2004.

[28] Kavanagh, L. PAD Partners: Social Sustainability and High Density Development PIA, Queensland Conference Paper: Brisbane, pp. 1-38, 2009.

[29] Boddy-Evans, A. Ubuntu. africanhistory.about.com/od/glossary/g/Ubuntu. htm

[30] Nortje, C. Personal communication, 2 May 2013, SAPD Sector Commander: Bridgeton, Oudtshoorn, SA.

[31] Wheelen, P. Personal communication, 6 May 2013, Western Cape Department of Human Settlements, City of Cape Town, SA.

[32] Crouse, P. Personal communication, 3 May 2013, Health Inspector: Oudtshoorn, SA.

[33] Andries, A. Personal communication, 3 May 2013. Health Inspector: Oudtshoorn, SA.

[34] Development Action Group. Sustainable medium-density housing. http://ftp.shf.org.za/DAGResBook_4_4.pdf

[35] Sivam, A. and Karuppannan, S., Density Design and Sustainable Residential Development. Institute for Sustainable Systems and Technologies (ISST),University of South Australia, Australia, pp. 1-12, 2011.

[36] Paulsen, L. and Silverman, M., Design strategies for the densification of low income housing, Congress on housing: Transforming housing environments through design. University of Pretoria, pp. 27-30, 2005.

[37] Coyne, W., The Fiscal Cost of Sprawl: How Sprawl Contributes to Local Governments' Budget Woes, Environment Colorado Research and Policy Centre, pp. 1-20, 2003.

[38] Carruthers, J.I. and Ulfarsson, F., Urban sprawl and the cost of public services, Environment and Planning B: Planning and Design, 30(4), pp. 503-522, 2003.

[39] Julies. Personal communication, 4 May 2013, Housing beneficiary. Oudtshoorn, SA. 